\title{
Prevalence of Myopia in children up to 16 years of age observed in tertiary care eye centre of central India
}

\author{
Gupta $R^{1}$, Sharma $B^{2}$, Anand $R^{3}$, Bawaria $S^{4}$, Kursange $S^{5}$ \\ ${ }^{1}$ Dr Rachna Gupta*, Associate Professor, ${ }^{2}$ Dr Bhavna Sharma*, Assistant Professor, ${ }^{3}$ Dr Reena Anand*, Director, ${ }^{4}$ Dr Shefali \\ Bawaria $\infty$, Senior Resident, Chhatisgarh Institute of Medical Sciences, Bilaspur $\infty$, CG, ${ }^{5}$ Dr Shubhangi Kursange*, Resident, \\ From Regional Institute of Ophthalmology, Gandhi Medical College, Bhopal*, India.
}

Address for correspondence: Dr Rachna Gupta, Email: drrachnagupta2k@gmail.com

\begin{abstract}
Introduction: Myopia is most common cause of childhood visual disability. In large population it remains undiagnosed. High myopia can be associated with major ophthalmic diseases such as myopic retinopathy and exudative myopic macular degeneration, myopic glaucomatous optic neuropathy and rhegmatogeneous retinal detachment. Methods: Study was conducted in Regional Institute of Ophthalmology in central India. Children up to age of 16 years were included, with special emphasis on observing type and amount of myopia and its clinical presentation. After mydriasis eyes were examined by retinoscopy and indirect ophthalmoscopy. Results: Prevalence of childhood myopia in hospital based study was $16.5 \%$ with male to female ratio 53:47. Most of the children were belonging to urban area (63.61\%). Headache was most common complain for hospital visit. Most common age group affected was 7-12 and 13-16 years. In 18.53\% of patients family history was present. Conclusion: Due to high magnitude of uncorrected Myopia it appears to be a public health problem both in urban and rural areas. An uncorrected refractive error leads to learning difficulties and reduced performances in school, ultimately affecting the psycho-social development of the child. For prevention Large-scale visual acuity screening programs must be launched to detect low vision due to myopia early and an annual check up to update the spectacle prescriptions.
\end{abstract}

\section{Introduction}

The term myopia was introduced from the habit which short-sighted people frequently have of half-closing the lids when looking at distant objects so that they may gain the advantages of a stenopic opening. Myopia also known as near sightedness is one of the leading cause of visual disability all over the world. In India little data is available for prevalence of myopia but it is most common form of correctable refractive error. Usually clinically presents with blurred distant vision, squeezing of eye and eye rubbing. Although school health programme for eye screening can diagnose a large number of student but only

Manuscript received: $06^{\text {th }}$ July 2013

Reviewed: $13^{\text {th }}$ July 2013

Author Corrected: $19^{\text {th }}$ Aug 2013

Accepted for Publication: $20^{\text {th }}$ Aug 2013 very few states are effectively running this programme. School myopia occurs between 5-15 years and stabilizes by the age of 20 years. Cause is idiopathic most of the time.

Asian Population has witnessed a major increase in the frequency of myopia, with a prevalence of myopia of as high as $80 \%$ in the 18 -year-old teenagers in some countries ${ }^{1-9}$. Distribution in various country and ethnic group varies.

The use of corrective lenses suggests that correctable visual impairment is the most common treatable chronic condition of childhood. Income, gender, and race/ethnicity are associated with having corrective lenses. The underlying causes and the impacts of these differences must be understood to ensure optimal delivery of eye care. $^{10}$

Available online at: www.ijmrr.in 99 | P a g e


Myopia in school children in one of the Asian study was associated with higher age, female gender, school type, parental myopia, higher socioeconomic background, dim reading illumination, longer daily studying duration, less rest during study, shorter duration of watching television (or computer), higher self-reported protein intake, feeling well about life and status, and feeling tired and dizzy ${ }^{11}$

Little data is available to know Prevalence of Myopia in Indian population. It varies between $2.77 \%$ to $7.4 \%{ }^{12,13}$ in different studies. According to the World Health Organization (WHO)-NPCB survey in 1989, 1.49\% population in India is blind of which $7.35 \%$ is due to refractive errors ${ }^{14}$. The proportion of blindness due to refractive error increased to $19.7 \%$ in the NPCB-National Blindness Survey even though the overall prevalence of blindness was reduced to $1.1 \%{ }^{15}$. In another study by Padhey AS et a ${ }^{16}$ Prevalence of myopia was $3.16 \%$ and $1.5 \%$ respectively in Urban and Rural India. Another Indian study has shown $4.74 \%$ prevalence in north india ${ }^{17}$

The prevalence of myopia has been reported to be as high as $70-90 \%$ in some Asian population with Taiwan reporting a myopic prevalence of $84 \%$ among $16-18$ - years - old high school students. ${ }^{18,19}$

Psychological changes also develop in children particularly in case of uncorrected myopia where they are growing in limited world. They started avoiding outdoor sports and prone to introspection. Limitations of intelligence and curtailment of interests leads to development of backwardness and stupidity in children. Another study has reported that preschoolers with uncorrected ametropia had significant reduction in visual-motor function.

As per compressive vision care in urban communities: the pediatric outreach program, early identification and treatment of abnormal visual conditions ensure that children have maximal visual acuity and function.

This study was attempted to measure the prevalence of myopia leading to visual acuity of less than $6 / 12$ in either eye in children in central India and to evaluate factors associated with myopia in children of less than 16 years.

\section{Material and methods}

This study was undertaken at tertiary eye care centre of central India, Regional Institute of Ophthalmology, Bhopal. 3056 children up to 16 yrs were screened for type and amount of ametropia with special emphasis on observing type and amount of myopia and its clinical presentation. It was a cross sectional hospital based study.

Inclusion criteria: children up to $16 \mathrm{yrs}$

Exclusion criteria: children $>16$ yrs, children with history of ocular trauma/ ocular surgery were excluded.

The demographic profile of patients was recorded in terms of name, age, sex, address, socioeconomic status. Detailed history of patients was taken and the chief complaints were noted in chronological order in three categories-

1) Ocular complaints-heaviness/pain in eyes/recurrent redness /deviation of eyes

2) Visual complaints- difficulty in reading/defective vision for distance or near

3) Referred complaints- heaviness of head or headache, history of nausea or vomiting

Family history of refractive error in siblings and parents, cerebral palsy or Down's syndrome and other relevant neurobehavioral abnormalities were recorded. Personal history and any significant antenatal, perinatal and postnatal history were noted.

Visual acuity was noted and detailed ocular examination with slit lamp and indirect ophthalmoscope was performed to look for any ocular morbidity.

\section{Assessment of refractive error:}

Retinoscopy was done to evaluate the type and amount of myopia and fundus examination was done to evaluate any posterior segment involvement under mydriasis. The cycloplegic used atropine $1 \%$ eye ointment/ homatropine $0.5 \%$ eye drop/ cyclopentolate/ tropicamide eye drops. 


\section{Results}

Table No 1: Prevalence of Ametropia in children attending eye OPD

\begin{tabular}{|c|c|c|c|}
\hline S. No. & No of pediatric pts & No of Ametropic children & No of myopic pts \\
\hline 1 & 3056 & 1230 & 505 \\
\hline
\end{tabular}

The prevalence of ametropia in children was found to be $40.24 \%$.Out of 1230 ametropic children, myopia was found in $41.05 \%$ children. Prevelance of childhood myopia in hospital based study was 16.5\%. Male to female child ratio was 53: 47 and around two third (63.61\%) of the population were belonging to below poverty line (BPL) category. $59.18 \%$ of children were belonging to urban areas.

Table No 2: Clinical Profile of Ametropic Children attending eye OPD (n=1230)

\begin{tabular}{|l|l|c|c|}
\hline S. No. & Complaints & No. of cases & \% \\
\hline 1 & Goes close to television & 756 & 75.04 \\
\hline 2 & Unable to see blackboard & 923 & 7.96 \\
\hline 3 & Frequent blinking/frequent rubbing of & 98 & 7.96 \\
\hline 4 & Redness of eyes & 98 & 49.02 \\
\hline 5 & Watering & 603 & 4.55 \\
\hline 6 & Recurrent swelling of lids & 56 & 69.59 \\
\hline 7 & Eyeache & 856 & 82.19 \\
\hline 8 & Headache & 1011 & 6.8 \\
\hline 9 & Change in palpebral aperture & 84 & 1.86 \\
\hline 10 & Deviation of eyes & 23 & 0.16 \\
\hline 11 & Frequent fall & 213 & 17.31 \\
\hline 12 & Picked up in school & & \\
\hline
\end{tabular}

It was found that ametropic children presented with varied clinical profiles. Headache was the most common presentation, accounts for $82.19 \%$.

Table No 3: Age distribution and degree of myopia in children

\begin{tabular}{|c|c|c|c|c|c|c|c|c|}
\hline \multirow{2}{*}{$\begin{array}{c}\text { Degree of myopia } \\
\text { diopter(D) }\end{array}$} & \multicolumn{9}{|c|}{ Age groups in yrs } \\
\cline { 2 - 9 } & $\mathbf{0 - 3}$ & $\mathbf{4}$ & $\mathbf{4 - 6}$ & $\%$ & $\mathbf{7 - 1 2}$ & $\%$ & $\mathbf{1 3 - 1 6}$ & $\%$ \\
\hline$<-2$ & - & - & 30 & 1.21 & 220 & 8.94 & 218 & 8.86 \\
\hline $\mathbf{- 2}$ to -6 & - & - & 64 & 2.61 & 232 & 9.43 & 226 & 9.18 \\
\hline$>-6$ & - & - & 2 & 0.08 & 8 & 0.32 & 10 & 0.40 \\
\hline Total no of eyes & - & - & 96 & 3.90 & 460 & 18.69 & 454 & 18.45 \\
\hline
\end{tabular}

As per the table maximum prevalence was observed in age group 7-12 and 13-16 years. 
Table No. 4: Distribution of degree of myopia

\begin{tabular}{|c|c|c|}
\hline Degree of myopia & No of eyes & \% \\
\hline$<-2$ D & 468 & $19.02 \%$ \\
\hline-2 to -6 D & 522 & $0.8 \%$ \\
\hline$>-6 D$ & 20 & \\
\hline Total & 1010 & \\
\hline
\end{tabular}

Mild to moderate type of Myopia were more common than severe one.

Table No 5: Distribution of Myopic Astigmatism

\begin{tabular}{|c|c|c|c|c|c|c|c|c|c|c|c|c|c|c|c|c|}
\hline \multirow{4}{*}{$\begin{array}{l}\text { Amount of } \\
\text { myopic } \\
\text { In diopters } \\
\text { (D) }\end{array}$} & \multicolumn{16}{|c|}{ Astigmatism } \\
\hline & \multicolumn{4}{|c|}{ With the rule } & \multicolumn{4}{|c|}{ Against the rule } & \multicolumn{4}{|c|}{ Oblique } & \multicolumn{4}{|c|}{ Bi-oblique } \\
\hline & \multicolumn{2}{|c|}{ No. of eyes } & \multicolumn{2}{|c|}{$\%$} & \multicolumn{2}{|c|}{ No. of eyes } & \multicolumn{2}{|c|}{$\%$} & \multicolumn{2}{|c|}{ No. of eyes } & \multicolumn{2}{|c|}{$\%$} & \multicolumn{2}{|c|}{ No. of eyes } & \multicolumn{2}{|c|}{$\%$} \\
\hline & $\mathbf{M}$ & $\mathbf{F}$ & $\mathbf{M}$ & $\mathbf{F}$ & $\mathbf{M}$ & $\mathbf{F}$ & $\mathbf{M}$ & $\mathbf{F}$ & $\mathbf{M}$ & $\mathbf{F}$ & $\mathbf{M}$ & $\mathbf{F}$ & $\mathbf{M}$ & $\mathbf{F}$ & $\mathbf{M}$ & $\mathbf{F}$ \\
\hline$<-2$ & 44 & 96 & 1.78 & 3.90 & 50 & 80 & 2.03 & 3.25 & 14 & 16 & 0.56 & 0.65 & 10 & 12 & 0.40 & 0.48 \\
\hline-2 to -6 & 58 & 62 & 2.35 & 2.52 & 48 & 38 & 1.95 & 1.54 & 14 & 16 & 0.56 & 0.65 & 4 & 6 & 0.16 & 0.24 \\
\hline$>-6$ & 2 & 2 & 0.08 & 0.08 & 4 & 6 & 0.16 & 0.24 & - & 2 & - & 0.08 & - & - & - & - \\
\hline Total & 104 & 160 & 4.22 & 6.50 & 102 & 134 & 4.14 & 5.44 & 28 & 34 & 1.13 & 1.38 & 14 & 18 & 0.56 & 0.73 \\
\hline
\end{tabular}

Out of total eyes examined myopic astigmatism of $<-2 \mathrm{D}$ with the rule was observed in $1.78 \%$ males and $3.90 \%$ females.

Table No 6: Family History of Refractive Error in Pediatric Ametropic Eyes $(n=2460)$

\begin{tabular}{|c|c|c|c|c|}
\hline Type of refractive error & $\begin{array}{c}\text { Refractive error in } \\
\text { parents }\end{array}$ & $\mathbf{\%}$ & $\begin{array}{c}\text { Refractive error in } \\
\text { siblings }\end{array}$ & $\%$ \\
\hline Myopia & 228 & 18.53 & 159 & 12.92 \\
\hline Hypermetropia & 96 & 7.80 & 112 & 9.10 \\
\hline Astigmatism & 121 & 9.83 & 178 & 14.47 \\
\hline Total no of eyes & 445 & 36.16 & 449 & 36.49 \\
\hline
\end{tabular}

Family history was present in $18.53 \%$ parents and $12.92 \%$ siblings in myopic patients.

Around $7.80 \%$ of male and $8.29 \%$ of female child were also having Anisometropia while Amblyopia was present in $0.88 \%$ of total eyes examined. Around 3.90\% cases with myopia $<-2$ D, $2.11 \%$ with-2D to $-6 \mathrm{D}$, and $0.32 \%$ with $>-6 \mathrm{D}$ had Exophoria. $0.08 \%$ eyes with myopia $<-2$ D, $0.16 \%$ with -2 D to -6 D and $0.08 \%$ with $>-6$ D had Exotropia.

\section{Discussion}

Myopia, in particular high myopia, can be associated with major ophthalmic diseases such as myopic retinopathy, exudative myopic macular degeneration, myopic glaucomatous optic neuropathy, rhegmatogeneous retinal detachment, as tears and haemorrhages. In this hospital based study we have noted that around $16.5 \%$ of total children had myopia. Other Indian studies has shown prevalence between $2.77 \%$ to $7.4 \%{ }^{12,13}$. One Indian study has shown prevalence of $3.16 \%$ and $1.5 \%$ respectively in Urban and Rural India ${ }^{16}$. Another Indian study has shown $4.74 \%$ prevalence in North india ${ }^{17}$. Higher prevalence in Available online at: www.ijmrr.in 102 | P a g e 
our study can be explained because it was a hospital based study. Czepita et al. noted that gender influences the occurrence of myopia and hyperopia in school-going children of age ranging from 6 to 18 years ${ }^{20}$. In our study $53 \%$ were male child while $47 \%$ were female. It may be associated with gender bias in our community. Skewed male to female child ratio may also be responsible.

More number of patients in our study belongs to below poverty line (BPL) group with odds ratio 1.5. It may be because of less available medical facility for poor population. $59 \%$ of our children were from urban population. Higher prevalence of myopia in urban population was also noted in other study from India. Dandona et al. ${ }^{21}$ in Andra Pradesh Eye Diseases Study (AEPDS) also noted that urban location was a predictor of myopia, and children of urban area had 2.5 times higher risk compared to rural children. Some of the study from Toiwan $^{22}$ and $\mathrm{Oman}^{23}$ has had similar results

Near work is one of the most frequently cited risk factor for myopia, and several observations support this hypothesis. Environmental factors such as progressively more competitive education system may have had an increasing impact in recent years. Moreover, environmental factors such as educational level, occupation and individual income have been shown to associate with the prevalence of myopia ${ }^{24,25}$

A positive correlation between the prevalence of myopia with age and the increasing prevalence of myopia with higher studies lends a strong support to close work theory in myopia development because in higher classes students tend to spend more time on studies. In this study $18.53 \%$ myopic cases were having history of ametropia in parents and $12.92 \%$ in sibling. Other study had shown positive family history as a risk factor for myopia ${ }^{26}$.

\section{Conclusion}

There is no well-established or universally accepted treatment for the prevention of myopia onset or progression. Due to high magnitude of uncorrected Myopia it appears to be a public health problem both in urban and rural areas. It has been given high priority under the National Programme for Control of Blindness.

The school vision-screening programme is fully sponsored by the Government of India and free spectacles are provided to poor children. The programme is aimed to eliminate blindness due to refractive error by providing refractive error services at primary level with the availability of qualified paramedical ophthalmic assistants in the vision centre for every 50,000 population by the year 2020 .

Although it is well structured centre sponsored programme but most of the states are not able to implement this programme. It leads to large number of uncorrected refractive errors. An uncorrected refractive error leads to learning difficulties and reduced performances in school, ultimately affecting the psycho-social development of the child.

There is need that National blindness control programme should be integrated with the Serve Shiksha Abhyaan (SSA) programme and there should be mandatory school vision screening at regular interval in all the schools.

Large-scale visual acuity screening programs must be launched to detect low vision due to myopia early and an annual check up to update the spectacle prescriptions. Public and school-based health education programs may also be targeted at the very young age. School teacher should be involved for positive reinforcement of school children for screening.

\section{Funding: Nil}

Conflict of interest: Nil

\section{Permission from IRB: Yes}

\section{References}

1. Lin LL, Shih YF, Hsiao CK, Chen CJ (2004) Prevalence of myopia in Taiwanese school children: 1983-2000. Ann Acad Med Singapore 33: 27-33 
2. Zhao JL, Pan XJ, Sui RF, Munoz SR, Sperduto RD, et al. (2000) Refractive error study in children: results from Shunyi district, China. Am J Ophthalmol 129: 427-435.

3. He M, Zeng J, Liu Y, Xu J, Pokharel GP, et al. (2004) Refractive error and visual impairment in urban children in southern China. Invest Ophthalmol Vis Sci 45: 793-799.

4. Saw SM, Goh PP, Cheng A, Shankar A, Tan DT, et al. (2006) Ethnicity-specific prevalences of refractive errors vary in Asian children in neighbouring Malaysia and Singapore. Br J Ophthalmol 90: 1230-1235.

5. Saw SM, Chan YH, Wong WL, Shankar A, Sandar M, et al. (2008) Prevalence and risk factors for refractive errors in the Singapore Malay Eye Survey. Ophthalmology 115: 1713-1719.

6. Zhang M, Li L, Chen L, Lee J, Wu J, Yang A, Chen $\mathrm{C}, \mathrm{Xu} \quad \mathrm{D}$, Lam DS, Sharma A, Griffiths S, Gao Y, Congdon N.. Population density and refractive error among Chinese children. nvest Ophthalmol Vis Sci. 2010 Oct;51(10):4969-76

7. Wong TY, Foster PJ, Hee J, Ng TP, Tielsch JM, Chew SJ, Johnson GJ, Seah SK. Prevalence and risk factors for refractive errors in adult Chinese in Singapore..Invest Ophthalmol Vis Sci. 2000 Aug;41(9):2486-94.

8. Xu L, Li J, Cui T, Hu A, Fan G, Zhang R, Yang H, Sun B, Jonas JB. Refractive error in urban and rural adult Chinese in Beijing. Ophthalmology. 2005 Oct;112(10):1676-83.

9. Liang YB, Wong TY, Sun LP, Tao QS, Wang JJ, Yang XH, Xiong Y, Wang NL, Friedman DS (2009) Refractive errors in a rural Chinese adult population the Handan eye study. Ophthalmology. 2009 Nov;116(11):2119-27

10. Kemper AR, Bruckman D, Freed GL. Prevalence and distribution of corrective lenses among school-age children. Optom Vis Sci. 2004;81:7-10
11. Qi Sheng You, Li Juan Wu, Jia Li Duan, Yan Xia Luo, Li Juan Liu, Xia Li, Qi Gao, Wei Wang, Liang Xu, Jost B. Jonas, Xiu Hua Guo. Factors Associated with Myopia in School Children in China: The Beijing Childhood Eye Study . PLoS One. 2012; 7(12): e52668.

12. Jain IS, Jain S, Mohan K. The epidemiology of high myopia: Changing trends. Indian Ophthalmol. $1983 ; 31: 723-8$.

13. Murthy GV, Gupta SK, Ellwein LB, Muñoz SR, Pokharel GP, Sanga L, et al. Refractive error in children in an urban population in New Delhi. Invest Ophthalmol Vis Sci. 2002;43:623-31

14. Mohan M. NPCB-WHO Report. New Delhi: Ministry of Health and Family Welfare, Government of India; 1989. National survey of blindness-India.

15. Murthy GV, Gupta SK, Bachani D, Jose R, John N. Current estimates of blindness in India. $\mathrm{Br} \mathrm{J}$ Ophthalmol. 2005;89:257-60.

16. Amruta S. Padhye, Rajiv Khandekar, ${ }^{1}$ Sheetal Dharmadhikari, Kuldeep Dole, Parikshit Gogate, and Madan Deshpande. Prevalence of Uncorrected Refractive Error and Other Eye Problems Among Urban and Rural School Children. Middle East Afr J Ophthalmol. 2009 AprJun; 16(2): 69-74.

17. Ishfaq Ahmed, ${ }^{1}$ Seema Mian, ${ }^{2}$ Syed Mudasir, ${ }^{3}$ and K. I. Andrabi. Prevalence of Myopia in Students of Srinagar City of Kashmir, India. Int J Health Sci (Qassim). 2008 Jan; 2(1): 77-81.

18. Pan CW, Ramamurthy D, Saw SM. Worldwide prevalence and risk factors for myopia. Ophthalmic Physiol Opt. 2012;32:3-16.

19. Lin LL, Shih YF, Hsiao CK, Chen CJ. Prevalence of myopia in Taiwanese schoolchildren: 1983 to 2000. Ann Acad Med Singapore. 2004;33:27-33.

20. Czepita D, Mojsa A, Ustianowska M, Czepita M, Lachowicz E. Role of gender in the occurrence of refractive errors. Ann Acad Med Stetin. 2007;53:5-7. 
21. 16. Dandona R, Dandona L, Naduvilath TJ, Srinivas M, McCarty CA, Rao GN. Refractive errors in an urban population in Southern India: The Andhra Pradesh Eye Disease Study. Invest Ophthalmol Vis Sci. 1999;40:2810-8.

22. Lin LL, Shih YF, Hsiao CK, Chen CJ, Lee LA, Hung PT. Epidemiologic study of the prevalence and severity of myopia among schoolchildren in Taiwan in 2000. J Formos Med Assoc. 2001;100:684-91

23. Lithander J. Prevalence of myopia in school children in the Sultanate of Oman: A nation-wide study of 6292 randomly selected children. Acta Ophthalmol Scand. 1999;77:306-9.
24. Simensen B, Thorud LO. Adult onset myopia and occupation. Acta Ophthalmol. 1994;72:469-71.

25. Leibowtiz HM, Krueger DF, Maunder LR, Milton RC, Kini MM, Kahn HA, et al. The framingham eye study monograph: An ophthalmological and epidemiological study of cataract, glaucoma, diabetic retinopathy, macular degeneration, and visual acuity in a general population of 2,631 adults, 1973-1975. Surv Ophthalmol. 1980; 24:472-9.

26. French AN, Morgan IG, Mitchell P, Rose KA. Risk Factors for Incident Myopia in Australian Schoolchildren: The Sydney Adolescent Vascular and Eye Study. Ophthalmology. 2013 May 11. pii: S0161-6420 (13) 00213-3

\section{How to cite this article?}

Gupta R, Sharma B, Anand R, Bawaria S, Kursange S. Prevalence of Myopia in children up to 16 years of age observed in tertiary care eye centre of central India. Int J Med Res Rev 2013;1(3):99-105. doi: 10.17511/ijmrr.2013.i03.06 